\title{
Woodland reserves within an urban agglomeration as important refuges for small mammals
}

\author{
Jakub Gryz ${ }^{1}$, Grzegorz Lesiński ${ }^{2}$, Dagny Krauze-Gryz ${ }^{3} \bowtie$, Przemystaw Stolarz $^{4}$ \\ ${ }^{1}$ Forest Research Institute, Department of Forest Ecology, Sękocin Stary, Braci Leśnej 3, 05-090 Raszyn, Poland \\ ${ }^{2}$ Warsaw University of Life Sciences - SGGW, Faculty of Animal Sciences, Ciszewskiego 8, 02-786 Warsaw, Poland \\ ${ }^{3}$ Warsaw University of Life Sciences - SGGW, Faculty of Forestry, Department of Forest Zoology and Wildlife \\ Management, Nowoursynowska 159, 02-776 Warsaw, Poland, phone: +48 225938 181, fax: +48 225938 145, \\ e-mail: dagny.krauze@wl.sggw.pl \\ ${ }^{4}$ Medical University of Warsaw, Banacha 1a, 02-097 Warsaw, Poland
}

\section{Abstract}

The aim of the study was to determine the species richness (S, Chao- 1 index) and diversity (Shannon-Wiener H' index, diversity profiles) of small mammal assemblages in woodland reserves in an urban agglomeration and to compare the similarity of assemblages (with the use of Ward's method) in terms of proportions of small mammals connected to the habitats of different level of naturalness. The work was conducted from 2004-2015 at 9 woodland reserves in Warsaw (Poland). On the basis of the analysis of pellets of tawny owls Strix aluco, 2792 individuals were identified (24 species). Reserves supported from 7 to 16 of the small mammal species, the highest overall number of species estimated (Chao-1) was 19. Species present in every reserve were Apodemus flavicollis, A. agrarius, Rattus norvegicus, Sorex araneus and Talpa europaea. Least frequent were Microtus agrestis and M. subterraneus. Seven species of bats were detected. Species diversity was lower in the biggest forest complexes, where forest rodents dominated small mammal assemblage. The heterogeneity of habitats within reserve and in the surroundings, in combination with limited human-interference, resulted in an increase in the species diversity. Overall, the reserves under study were an important refuge for small mammals within the Warsaw agglomeration. However, safeguarding of adjacent areas against excessive anthropogenic change is needed and ecological corridors that link different areas need to be retained.

\section{KEY WORDS}

rodents, soricomorphs, bats, urbanisation, habitat fragmentation, tawny owl pellets

\section{INTRODUCTION}

Urbanisation leads to the destruction of woodlands adjacent to towns and cities. The process is happening most rapidly near large metroplexes with well-developed industries and growing human populations (Faulkner 2004; review in Marzluff et al. 2008). Woodlands or forests close to large cities are subject to broad-scale changes, typically the construction of building plots, the development of features, such as wastewater treat- 
ment plants, landfills for the disposal of waste, roads or cemeteries. In extreme cases, especially near city centres, widespread deforestation and the removal of tree cover can be very common. Often, the only means of restricting the influence of urbanisation to areas of woodland located within city limits is to protect areas of woodland by making them nature reserves (Laszek and Sendzielska 1989; Wojtatowicz 2005).

Highly-urbanised areas, and in particular the areas located in the centres of large metroplexes, are invariably characterised by impoverished mammal faunas, especially small mammal faunas (Goszczyński et al. 1993; McKinney 2008). In urban environments, factors that reduce the richness and diversity of small mammal assemblages (especially those characteristic of woodland or forest) include the fragmentation of forest and woodland, as well as the isolation that increasingly characterises remaining patches (Dickman and Doncaster 1987; Baker et al. 2003; Gomes et al. 2011; Łopucki et al. 2013). Despite being protected, woodland reserves established within metroplexes tend to be characterised by an impoverished mammal fauna. For example, the Australian reserves of this type in cities have a third fewer native species of small mammals than those located outside of cities (Buckmaster et al. 2010). Never-

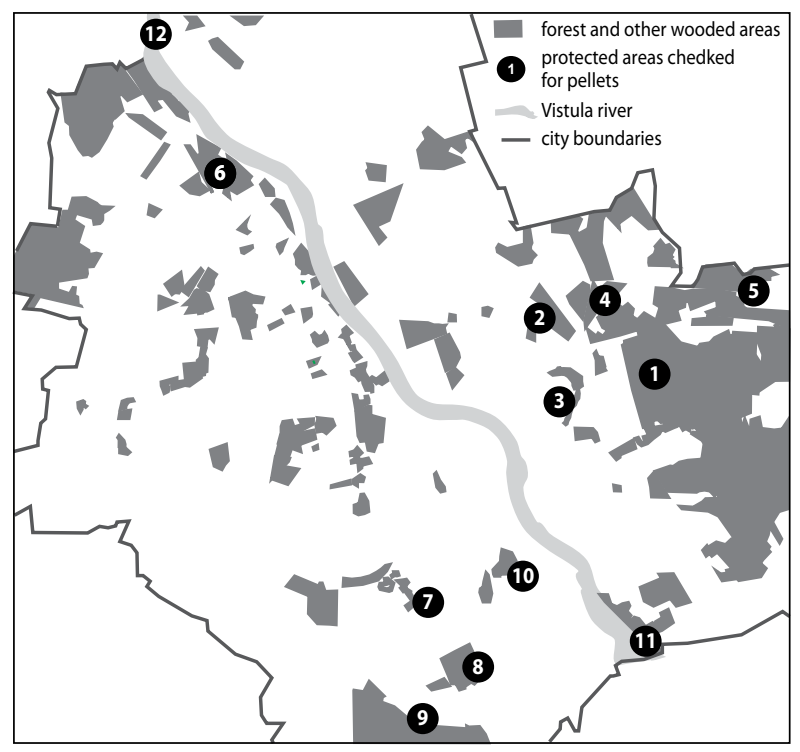

Figure 1. Distribution of woodland reserves in Warsaw. Pellets were found in sites 1-9. No pellets were found in sites 10-12. The numbers of sites refer to the numbers and site names given in table 1 theless, the establishment of reserves may still increase the suitability of the habitat after several years of protection (Lesiński and Gryz 2012). Even within city limits, the composition of small-mammal assemblages differs markedly across an urbanization gradient, with lower species richness and dominance of species connected to markedly transformed habitats typical for central zone (Gryz et al. 2008).

The aim of this work was to characterise the small mammal fauna of woodland reserves established within a large urban area. The number of species and species diversity was compared between different sites. In addition, the quality of habitat present at different sites and the role that reserves played in protecting small mammals were assessed.

\section{MATERIAL AND METHODS}

\section{Study sites}

This work was conducted in Warsaw, Poland's capital and largest city, with almost 2 million inhabitants. The pellets of tawny owls Strix aluco were searched within 12 of the city's woodland reserves. Finally, data from 9 of areas (Fig. 1) were used because in the three other reserves, either tawny owls were not recorded (Gryz and Krauze-Gryz 2013) or a sufficient number of pellets was not found. A characterisation of the sites is presented below. The data from literature (Laszek and Sendzielska 1989; Czerwiński et al. 2003; Wojtatowicz 2005; Luniak 2010; Stolarz 2011) and the author's own observations were used.

\section{Las im. Jana III Sobieskiego (the King Jan III Sobieski Wood)}

This woodland reserve has been protected since 1934 and covers 115 ha. The central and southern parts retain oak Quercus spp. stands over 170 years old, while other areas have stands dominated by oaks and Scots pines Pinus sylvestris with a mix of various broadleaved species. The reserve is part of a larger forest complex covering approximately 1000 ha. This area, which lacks natural watercourses or bodies of water, is connected to a limited degree with extensive forest areas located beyond the Warsaw city limits. Pellets were collected here during the years from 2009-2015 from three tawny owl territories. 


\section{Olszynka Grochowska}

This 57 ha reserve was established in 1983. The entire woodland complex is protected. It is surrounded by single-family housing and railway infrastructure. Scots pine, birch Betula pendula and oak are present in the tree stands, and wet areas support black alder Alnus glutinosa. A drainage channel is present in the southern part of the reserve. Pellets were collected from a single tawny owl territory during the years from 2011-2014.

\section{Zakole Wawerskie (Wawer Meander)}

This reserve is part of the old floodplain terrace of the River Vistula, which was established in 2002. Ninety percent of this wet 56 ha area is covered by natural stands of alder between 40 to 60 years in age. The western part also has meadowlands, reed beds and scrub habitats. The northern limits of this protected area are delimited by a canalised watercourse emptying into the Vistula. An area of more than 150 ha to the south is made up of meadow, pasture, arable land and wasteland. In contrast, land to the east and north of the Wawer Meander has become highly urbanised. Pellets were collected from a single tawny owl territory during the years 2011-2013.

\section{Kawęczyn}

This woodland reserve is 70 ha and was established in 1998. The reserve is bounded by two roads with heavy traffic and a rail line. However, there are adjacent woodlands that make the entire area of contiguous woods approximately 150 ha. This area is barely linked to the more extensive Olszynka Grochowska area and the Sobieski Wood. The stands in this area are primarily composed of Scots pine, oak and birch, though most of this site was only afforested in the 1950s. Pellets from a single tawny owl territory were collected here during the years 2010-2013.

\section{Bagno Jacka (Jacek Marsh)}

This area of nearly 20 ha was established in 1981 to protect a raised bog and transitional mire. Ninety percent of this reserve is occupied by forest up to 70 years old. Tree species primarily consist of Scots pine and birch. The peatland here is surrounded by pine stands that grow on mineral soils. To the south of the reserve, there are urbanised areas. On the other sides of the reserve, there are military training grounds that cover approximately
8000 ha. Pellets were obtained from a single tawny owl territory during the 2011-2014 period.

\section{Las Bielański (Bielany Wood)}

Since 1978, this area of 130 ha has been protected as a multi-species broadleaved woodland. Habitats in this reserve include oak-lime-hornbeam forest, riparian forest and alder carr. The protection of woodland extends to a rather large area of approximately $170 \mathrm{ha}$. The oldest oak stands here exceed 250 years in age. The reserve area is crossed by two small watercourses. On the eastern side, the reserve is partly separated from the River Vistula by a 3-lane expressway, while the northernmost limits are connected to the large Kampinos (Kampinoski) National Park, which extends up to the city limits of Warsaw. In contrast, urban development is present to the west and south. Pellets from the three tawny owl territories were collected here during the years from 2007-2014.

\section{Skarpa Ursynowska (Ursynów Scarp)}

This reserve protects the scarp rising above what was once the proglacial valley that carried meltwaters from the ice sheets. This valley is now considered to be the Vistula Valley. Protection was provided to a 23 ha area here in 1996, and the reserve includes a multi-species stand of broadleaved woodland. However, the woodland and scrub habitat only accounts for $30-40 \%$ of the protected area. The remainder of the reserve is composed of meadowland and ruderal plant associations. The scarp runs to the south of the reserve and is connected to woods present at the southern edge of the Warsaw agglomeration. To the southeast, the reserve borders have more extensive open areas, although these areas are destined for more urban development. Pellets from two tawny owl territories were collected here during the 2006-2012 period.

\section{Las NatoliĐski (Natolin Wood)}

A 105 ha area is protected since 1991. Although this land was formerly an area of parkland that extended around the residences of Polish magnates, spontaneous regenerations of woodland took place during the postWar period. The oldest stands of oak are more than 250 years old. Ash Fraxinus excelsior, elm Ulmus spp. and black alder are also well-represented in these woods. The reserve area also includes heritage buildings and 
open areas. To the west of the reserve are developed areas, while on the other sides, there are extensive areas of farmland, although farmland is diminishing because more and more plots are being sold to urban developers. Pellets from three tawny owl territories were collected during the years 2004-2011.

\section{Las Kabacki (Kabaty Wood)}

This is Warsaw's largest protected area, which covers more than 900 ha. Kabaty Wood was established in 1980. The multi-species tree stands here are dominated by Scots pines and oaks, which grow in fertile habitats. Some stands are more than 120 years old. The forest complex is surrounded by developed areas, except in the east, where the reserve is adjacent to arable land and an urban park. This reserve is contiguous with other tracts of land via the Vistula Scarp. Pellets from five tawny owl territories were collected here during the years from 2004-2010.

\section{Methods}

Inventory of the mammal fauna was conducted with the standard, non-invasive procedure of examining tawny owl pellets (Heisler et al. 2015). Alternative inventory methods, such as trapping (using a variety of different traps), invariably limit the number of species detected below the number actually present (Gortat et al. 2014). In addition, trapping is difficult to execute in areas that are heavily travelled by people. Trapping also often leads to unintended deaths of the animals under study (Gryz and Krauze 2007; Gryz et al. 2008). Analysis of the dietary composition of the tawny owls can offer a robust quantitative and qualitative reflection of the small vertebrate assemblage present in an area (Mikkola 1983; Gryz and Krauze 2007; Lesiński et al. 2008; Żmihorski et al. 2011; Heisler et al. 2015). The tawny owl is a rather sedentary species, which stays in a single territory throughout the year. This permits a high degree of certainty that the prey hunted by the owls was taken in areas close to where the pellets were collected. Depending on habitat type, the home ranges of tawny owls are known to cover between 10+ and several tens of hectares (Redpath 1995; Sunde and Bølstad 2004). Tawny owls are also known to be opportunistic feeders, thus, the study of their pellets may provide a robust estimate of the diversity of mammal species present, at least for the species of the following genera: Rodentia,
Soricomorpha, Chiroptera and Carnivora. However, in Europe, the adults of only two carnivorous species can be caught by tawny owl, that is least weasel Mustela nivalis and stoat Mustela erminea. In other cases, the juveniles are preyed upon. The tawny owl can consume prey as small as Poland's smallest bat or shrew species (weighing just a few grams), as well as large rodents whose weights may exceed $250 \mathrm{~g}$, such as the water vole Arvicola amphibius and brown rat Rattus norvegicus (Lesiński et al. 2009).

Pellets were collected on a regular (monthly, quarterly or half-yearly) basis to ensure that the diet of the tawny owls in all seasons of the year was represented. Subsequent laboratory analysis was based on standard procedures (Raczyński and Ruprecht 1974; Yalden and Morris 1990). Fragments of bone were identified using the key of Pucek (1984) or other detailed works (Ruprecht 1979, 1987). The material collected in the years 2004-2015 originated either within the protected areas under study or close to the reserve boundaries. Pellets were obtained beneath trees in places where tawny owls were considered to be commonly present. Some pellets were also taken from nest boxes or tree holes. Some of the data documenting the mammal fauna of the Bielany, Natolin and Kabaty Woods and Jacek Marsh reserves were also taken from the literature (Gryz and Krauze 2007; Lesiński and Gryz 2012; Stolarz and Lesiński 2012).

The results are presented in terms of the percentage of all the mammal individuals reported, that were accounted for by individuals of any given taxon. Species richness (S) was determined, as well as an estimate of the overall species richness of small and mediumsized mammals at a given site on the basis of the Chao-1 index. This index accounts for the number of species represented just once or twice in a given sample (Chao 1984). Species diversity was estimated using the $\ln$ based Shannon-Wiener H' index, but also by generating diversity profiles of Tothmeresz (1995). The latter takes species richness into account, as well as the ShannonWiener and Simpson diversity indices. To compare the diversities characteristic of different sites, a t-test was used to compare the diversities calculated using the Shannon formula as was proposed by Hutcheson (1970). The similarity of the species assemblages was compared using the Ward's method by calculating Euclidean distances. Statistical analyses were performed using the Past3 program (http://folk.uio.no/ohammer/past/). 


\section{Results}

Overall, the sites yielded the remains of 2792 individuals representing 24 species (Tab. 1). Species present at all sites were the yellow-necked mouse Apodemus flavicollis, striped field mouse $A$. agrarius, brown rat Rattus norvegicus, common shrew Sorex araneus and mole Talpa europaea. Also, widespread was the common vole Microtus arvalis, house mouse Mus musculus and bank vole Myodes glareolus, each of which was recorded in 8 of the 9 sites. The least widespread of the rodents reported was the field vole, Microtus agrestis, which was recorded at just two sites, and the pine vole $M$. subterraneus, root vole $M$. oeconomus and the wood mouse $\mathrm{Ap}$ odemus sylvaticus, each of which was present at 4 sites.

The highest proportions of woodland rodents (i.e., A. flavicollis and M. glareolus) among prey items were $77 \%$ observed in the Kawęczyn reserve, as well as $69 \%$ and $64 \%$ in the Kabaty Wood and Olszynka Grochowska sites, respectively. The voles associated with open areas were present at the highest frequencies at the Ja-

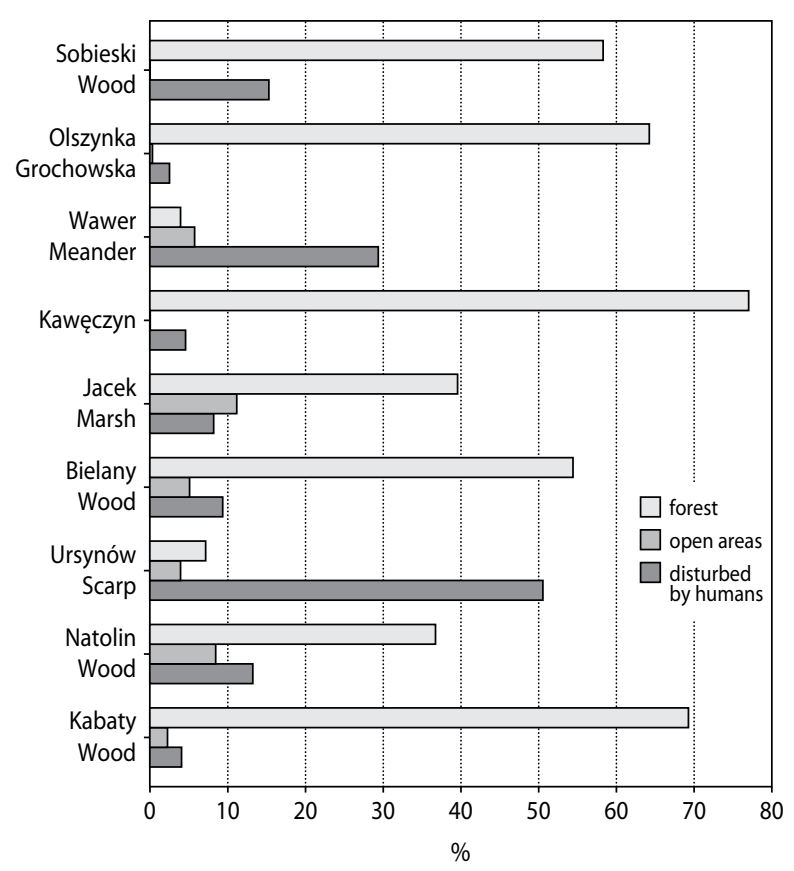

Figure 2. The assemblage of small mammal species presents in the Warsaw woodlands reserves as an index of degree of pristineness of the areas. Rodents are associated with either forests and woodlands (Myodes glareolus, Apodemus flavicollis), open areas (Microtus spp.), or areas disturbed by humans (Mus musculus, A. agrarius, Rattus norvegicus) cek Marsh (where they accounted for $11 \%$ of the overall assemblage), at Natolin Wood (8\%), and at the Wawer Meander, Bielany Wood, Ursynów Scarp and Kabaty Wood reserves. The rodents associated with the presence of human beings (Mus musculus, A. agrarius and $R$. norvegicus) accounted for the greatest proportions of the assemblages reported at the Usrynów Scarp and Wawer Meander sites (50\% and 29\%, respectively), the Olszynka Grochowska site, and the Sobieski and Natolin Woods (Fig. 2).

The Ward's method suggested that there was a faunal similarity between the Bielany reserve and the Kabaty Woods. However, the Jacek Marsh and Sobieski Wood sites were also included in the same group. A second group included the Wawer Meander and the Ursynów Scarp sites, as well as Kawęczyn and the Natolin Wood, with the latter forming two separate clusters alongside the separated Olszynka Grochowska (Fig. 3).

The numbers of species reported for different sites ranged from 7 (at the Kawęczyn reserve) to 16 (at the Jacek Marsh and the Bielany and Natolin Woods). There was no relationship between these numbers and either the reserve area $(\mathrm{r}=-0.06, P>0.05)$ or the sample size

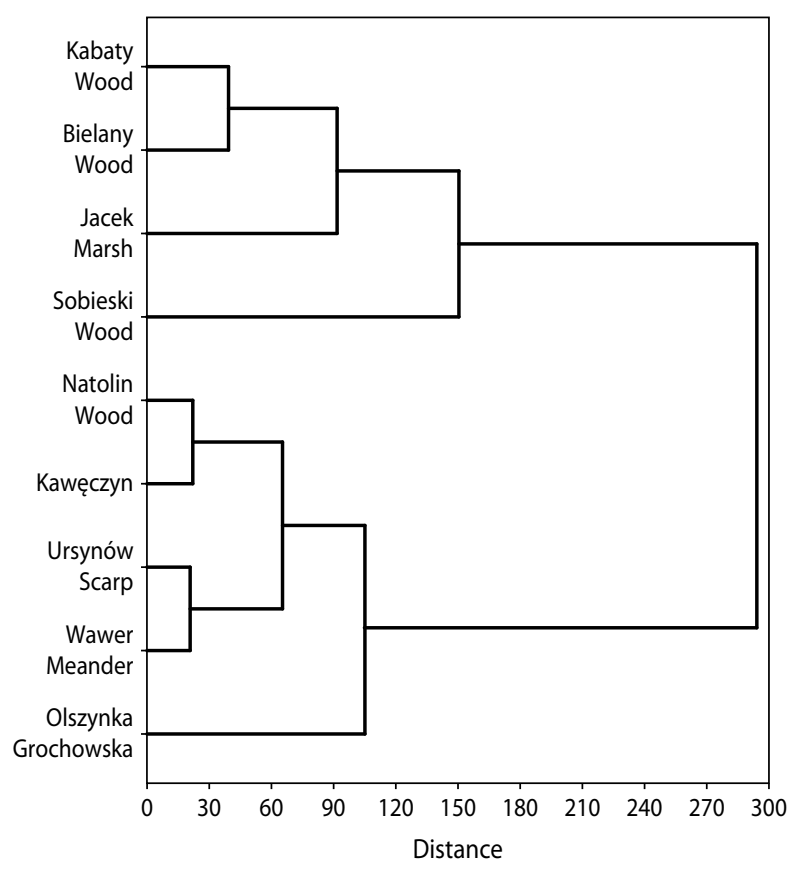

Figure 3. Euclidean distance-based cluster analysis using Ward's method that estimates the similarity in small mammal assemblages between sites 
Table 1. The percentage, species richness (reported - S or estimated - Chao-1) and diversity (Shannon-Wiener index - H') of small mammals detected in Warsaw woodland reserves based on the analysis of tawny owl pellets. Woodland reserves: Sobieski Wood (1), Olszynka Grochowska (2), Wawer Meander (3), Kawęczyn (4), Jacek Marsh (5), Bielany Wood (6), Ursynów Scarp (7), Natolin Wood (8), Kabaty Wood (9)

\begin{tabular}{|c|c|c|c|c|c|c|c|c|c|}
\hline \multirow{2}{*}{ Prey } & \multicolumn{9}{|c|}{ Study area } \\
\hline & 1 & 2 & 3 & 4 & 5 & 6 & 7 & 8 & 9 \\
\hline Microtus arvalis & 0.3 & 0.4 & 4.9 & & 10.7 & 4.8 & 3.2 & 6.0 & 2.4 \\
\hline M. oеconomus & & & & & 0.6 & 0.5 & 0.8 & 2.4 & \\
\hline M. agrestis & & & 0.8 & & 0.1 & & & & \\
\hline M. subterraneus & 0.3 & & & & & 0.5 & & 4.2 & 2.1 \\
\hline Microtus spp. & 2.1 & 1.7 & 14.6 & & 1.5 & 0.5 & 7.2 & 3.0 & 0.3 \\
\hline$\Sigma$ Microtus & 2.7 & 2.1 & 20.3 & & 12.8 & 6.1 & 11.2 & 15.7 & 4.9 \\
\hline Myodes glareolus & 33.4 & 41.8 & 1.6 & 30.3 & 17.2 & 15.2 & & 9.6 & 25.4 \\
\hline Apodemus flavicollis & 24.7 & 22.4 & 2.4 & 46.8 & 22.3 & 39.2 & 7.2 & 27.1 & 43.9 \\
\hline A. sylvaticus & 0.2 & 0.4 & 3.3 & & 1.2 & & & & \\
\hline A. agrarius & 13.4 & 16.5 & 26.0 & 2.8 & 6.9 & 7.0 & 34.4 & 10.8 & 3.8 \\
\hline Apodemus spp. & 13.1 & 8.4 & 14.6 & 11.9 & 22.8 & 17.5 & 21.6 & 17.5 & 11.8 \\
\hline Micromys minutus & & & 15.4 & & 2.3 & 0.7 & & 4.2 & 0.3 \\
\hline Mus musculus & 1.0 & 3.4 & 2.4 & 0.9 & 0.6 & 0.7 & 12.8 & 1.2 & \\
\hline Rattus norvegicus & 1.0 & 0.4 & 0.8 & 0.9 & 0.7 & 1.8 & 3.2 & 1.2 & 0.3 \\
\hline$\Sigma$ Rodentia & 89.5 & 95.4 & 87.0 & 93.6 & 86.9 & 88.2 & 90.4 & 87.3 & 90.6 \\
\hline Sorex araneus & 7.1 & 3.4 & 8.9 & 5.5 & 11.4 & 5.7 & 4.8 & 3.6 & 7.0 \\
\hline S. minutus & 2.6 & 0.8 & 0.8 & & 1.0 & 0.2 & & 1.2 & \\
\hline Talpa europaea & 0.5 & 0.4 & 3.3 & 0.9 & 0.3 & 2.7 & 4.8 & 2.4 & 1.7 \\
\hline Erinaceus roumanicus & & & & & & & & 0.6 & \\
\hline$\Sigma$ Soricomorpha and Erinaceomorpha & 10.2 & 4.6 & 13.0 & 6.4 & 12.7 & 8.6 & 9.6 & 7.8 & 8.7 \\
\hline Myotis nattereri & & & & & & & & 3.0 & \\
\hline M. daubentonii & & & & & & & & & 0.3 \\
\hline Eptesicus serotinus & & & & & & 1.1 & & & \\
\hline Nyctalus leisleri & & & & & & 0.2 & & & \\
\hline N. noctula & & & & & 0.1 & 1.4 & & 1.2 & \\
\hline Pipistrellus nathusii & & & & & 0.1 & & & & \\
\hline Plecotus auritus & & & & & 0.1 & 0.2 & & & \\
\hline Chiroptera indet. & 0.2 & & & & & 0.2 & & & \\
\hline$\Sigma$ Chiroptera & 0.2 & & & & 0.3 & 3.1 & & 4.2 & 0.3 \\
\hline Neovison vison & & & & & & & & 0.6 & \\
\hline Mustela nivalis & 0.2 & & & & & & & & 0.3 \\
\hline Number of prey items & 619 & 237 & 123 & 109 & 685 & 441 & 125 & 166 & 287 \\
\hline Number of species $-\mathrm{S}^{*}$ & 12 & 10 & 12 & 7 & 16 & 16 & 8 & 14 & 11 \\
\hline Chao-1* & 12.3 & 13.0 & 13.5 & 10.0 & 19.0 & 17.0 & 8.0 & 14 & 17 \\
\hline $\mathrm{H}^{\prime} *$ & 1.53 & 1.40 & 1.90 & 1.13 & 1.89 & 1.74 & 1.58 & 2.15 & 1.40 \\
\hline
\end{tabular}




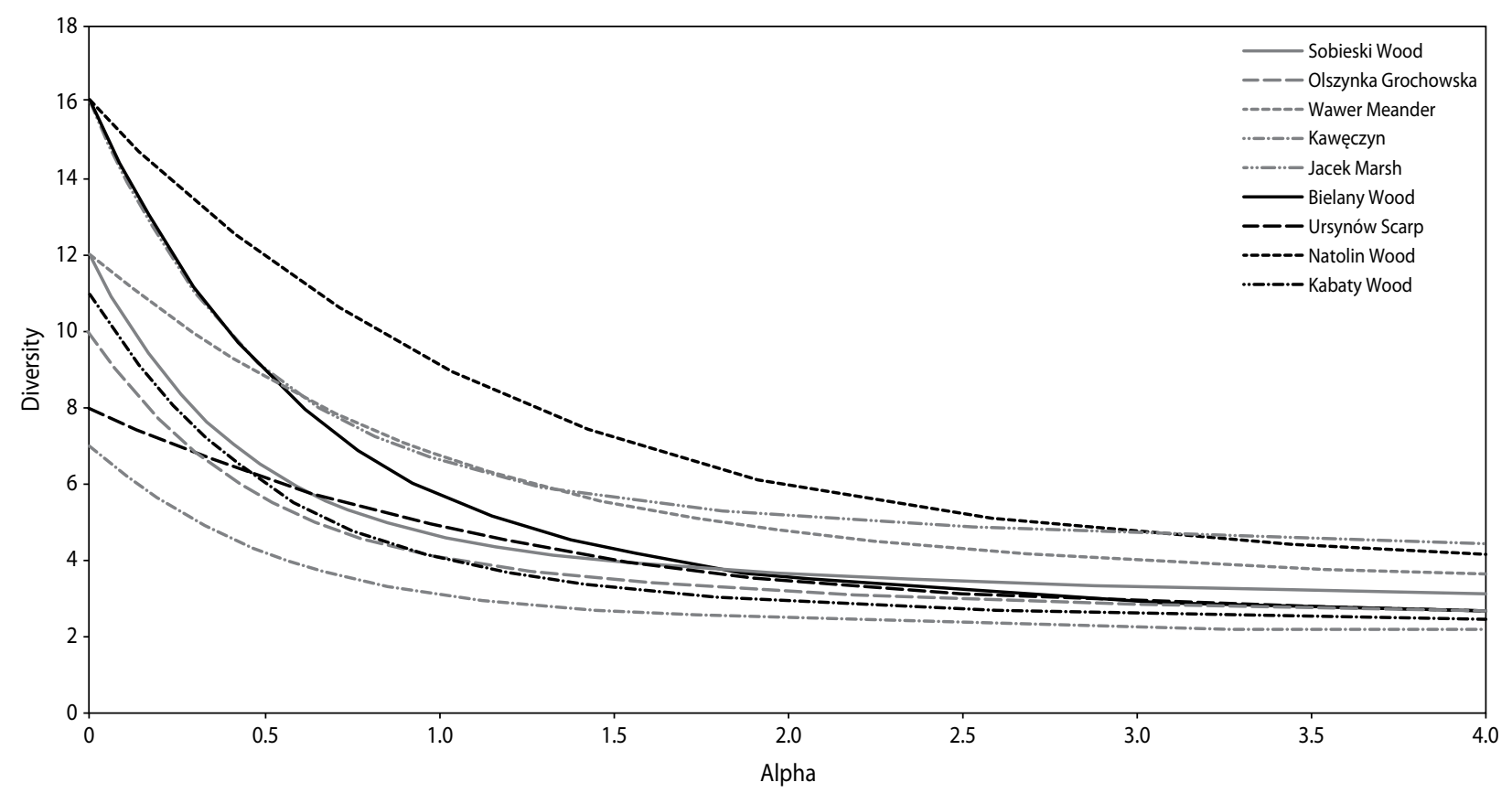

Figure 4. Species diversity profiles for the assemblages of small mammals present in Warsaw's woodland reserves

$(\mathrm{r}=0.60, P>0.05)$. The estimated overall species richness of small mammal species (Chao-1) was greatest at the Jacek Marsh reserve and smallest at the Ursynów Scarp reserve. The values for Chao-1 index were comparable with the numbers of species actually obtained for the Ursynów Scarp, Natolin Wood and Sobieski Wood reserves. In Olszynka Grochowska site, Jacek Marsh and Bielany Wood, the estimated numbers of species were greater by 3 than those actually reported, while in the case of Kabaty Wood, the difference between the estimated and observed values was highest and greater by 6 species (Tab. 1).

In turn, the diversity of species of small mammals was highest at the Natolin Wood site $\left(\mathrm{H}^{\prime}=2.21\right)$, followed by the Jacek Marsh (1.89). However, these two sites differed significantly in this regard $(\mathrm{t}=2.28$, $\mathrm{df}=189.96, \mathrm{p}<0.05)$. The lowest estimated value for diversity was for Kawęczyn reserve $\left(H^{\prime}=1.13\right)$. This value differed significantly from the values estimated for the Olszynka Grochowska site $\left(\mathrm{H}^{\prime}=1.40\right)(\mathrm{t}=-2.41$, $\mathrm{df}=186.37, \mathrm{p}<0.05)$ and the Kabaty Wood $\left(\mathrm{H}^{\prime}=1.39\right)$ $(t=2.30, d f=199.34, p<0.05)$. The species diversities of small mammal assemblages of the Kabaty Wood and Olszynka Grochowska were not found to differ significantly $(\mathrm{t}=-0.07, \mathrm{df}=464.61, \mathrm{p}>0.05)$.
The analyses of diversity profiles (Fig. 4) revealed that the highest diversity was at the Natolin Wood, however it was comparable to Jacek Marsh. Jacek Marsh had a similar profile to the Bielany Wood and the Wawer Meander reserves. A rather similar profile characterised the Sobieski and Kabaty Wood reserves, the Olszynka Grochowska site and the Ursynów Scarp, while the Kawęczyn reserve had the lowest diversity of all sites surveyed.

\section{Discussion}

Our study showed that the number of species recorded (as well as a total estimated number of species - Chao1) differed greatly between woodland reserves in Warsaw. Also, the analyses of species diversity (ShannonWiener H' index) indicated important discrepancies between areas. Nevertheless, when diversity profiles, based on species richness and the Shannon-Wiener H' and Simpson diversity indices (Tothmeresz 1995), were taken into account, it could be seen that only one site (Kawęczyn) was markedly different from all the others. Possible explanations for these results are discussed below. 
The greatest species diversity (reflected both by Shannon-Wiener H' index and diversity profiles), and relatively high levels of species richness, were observed in the Natolin Wood. This site also had the most even spread of species associated with forests (accounting for less than 50\%), open areas and human development. This high diversity reflects the heterogeneity of the habitat (i.e., the presence of extensive grasslands and water bodies) within the reserve (Krojerová-Prokešová et al. 2016), as well as the close proximity of both open and developed areas. In addition, this area of woodland only experiences limited human interference, indeed, the structure of this reserve is actually reminiscent of a primitive forest. In this case, a moderate level of urbanisation has promoted higher levels of species diversity, in a manner consistent with the 'intermediate disturbance hypothesis' (McKinney 2008). Similar number of small mammals was recorded in SW suburban zone of Warsaw, in a moderately transformed habitat with high percentage of vegetation cover (Romanowski et al. 2016). On the contrary, Kawęczyn was a reserve with the highest share of typical forest rodents (Myodes glareolus and Apodemus flavicollis). At the same time, the smallest number of species was reported from this reserve, as well as the smallest level of species diversity (both H' index and diversity profile). Nevertheless, the species characteristic of areas highly modified by human activity (Mus musculus, A. agrarius and $R$. norvegicus) here accounted for less than $5 \%$ of the overall small mammal assemblage. The results of this kind are analogous to those obtained from Białowieża National Park (Jędrzejewski et al. 1994; Gryz et al. 2012), an extensive forest with a low human-interference. Similar proportions for the frequency of occurrence of these two groups of rodents (i.e., connected to forests and human-transformed areas) were also obtained for the Kabaty Wood reserve. Here, a relatively small number of species was also detected, although the difference between the actually-recorded and the estimated overall species richness (Chao-1) was greatest, which suggests that with a bigger sample size a higher number of species would be probably recorded. In the case of the two aforementioned reserves, they either protect large complex of woodland or are a part of the bigger wood, so the presence of species connected to open/humantransformed areas is limited to forest edges. On the contrary, in the case of small woods, the higher 'edge effect' ensures the penetration by species associated with human-transformed areas (i.e., Apodemus agrar$i u s)$ or with open areas (i.e., voles), and their considerable share in total small-mammal assemblage.

Previous studies from Warsaw showed that urbanization influenced the species composition of rodents, with striped-field mouse being a dominant species (and reaching extreme densities) in considerably human-transformed habitats (i.e., parks, cemeteries, etc.) (Babińska-Werka et al. 1979; Gortat et al. 2014). So, this is the species whose share in the small-mammal assemblage can be an index of the level of naturalness of the woodland area. In this view, the Ursynów Scarp reserve could be defined as the least pristine among all the reserves studied. The only woodland species present at this site was yellow-necked mouse, but it only accounted for a small portion of the overall assemblage. In fact, the species most abundant here were those characteristic of areas extensively disturbed by humans and they accounted for more than half of all of the specimens recorded, and a proportion of $A$. agrarius was the highest (as compared to other reserves). This site also had low species richness and relatively low species diversity. The Ursynów Scarp is a small area located well within the city, with neighbourhood areas that are partially built-up. The findings here are thus consistent with those from other studies, where urbanisation has resulted in a decrease in species diversity and richness. These studies have also found that urbanisation also decreases the representation of native species (Cavia et al. 2009) and the proximity to developed areas generally reduces the diversity of mammal species (Dickman 1987).

The areas with a high level of species richness recorded were the Jacek Marsh and Bielany Wood. The first of these is a fragment of suburban woodland that is connected to larger areas of forest beyond the city. Thus, the species that were rare in the metroplex, such as the Microtus agrestis, were present in this reserve. Three species of bats have also been reported there. The other reserve, the Bielany Wood has the greatest number of bat species (4), along with three Microtus species. At the same time, woodland rodents made up over $50 \%$ of the small mammals detected at this site. In this woodland, changes in small-mammal community were recorded over last decades as a result of legal 
protection and restoration of stands, with an increase of $A$. flavicollis and soricomorphs, and a decrease of $A$. agrarius, Rattus norvegicus and M. musculus (Lesiński et al. 2012).

Although voles are typical for open area, they are absent (on the contrary to field-stripped mouse), from the central quarters of Warsaw (Gryz et al. 2008), and their share in rodent community decreases with an urbanization gradient (Andrzejewski et al. 1978; Gortat et al. 2014). Therefore, in our study they were present in all but one (Kawęczyn) woodland reserves, but their share was highest in sites that were surrounded by or connected to open areas such as meadows or arable lands (i.e., Wawer Meander, Ursynów Scarp, Natolin Wood). In the case of the Jacek Marsh voles (i.e. Microtus arvalis) were probably caught at the road/railway embankment, covered with low-cut grass and regularly mown, which marked the edge of the reserve. It can be assumed that small-mammal assemblage of agricultural lands surrounding the woodland reserves under this study is relatively high. Due to changes in land use within city borders, they are often represented by fallow or set-aside land, old orchards. Such habitats are known to support higher biodiversity of small mammals than intensively cultivated fields (Janova and Heroldová 2016).

The group of small mammals that are very sensitive to habitat fragmentation are shrews (Vergnes et al. 2013). In Warsaw, they are absent from green areas located in the central quarters (Gryz et al. 2008; KrauzeGryz et al. 2016) and areas of high anthropopressure degree (Gortat et al. 2014). Nevertheless, they were present in all the studied woodland reserves. It may be assumed that the woodland reserves under study were big enough to maintain viable population of shrews.

Bats can be regarded as prey species caught most often by chance. In all of the areas studied, it may be possible to record more bat species as the list of bat species of the Warsaw agglomeration counts 15 (Lesiński et al. 2001; Popczyk et al. 2008).

None of the representatives of the dormouse family Gliridae were recorded in this study. The closest known localities for the hazel dormouse Muscardinus avellanarius are in the Kampinos Forest, which is mostly National Park land (Lesiński et al. 2013) or a part of the Mazowiecki Landscape Park (Lesiński and Gryz 2008). Another species rarely recorded in areas developed by humans is the northern birch mouse Sicista betulina, which was recorded relatively close to the Jacek Marsh reserve (Lesiński et al. 1998), but has never been reported from the Warsaw agglomeration.

Woodland reserves under this study offered variable conditions for small mammals. This was due to their history, habitat structure within the reserve and in the surroundings, as well as human interference. However, according to Ward's method, similarities were found. For example, the Wawer Meander and the Ursynów Scarp reserves, which formed one group, are both strictly connected to Vistula floodplain, both are longnarrow woods, surrounded by open, at least partially wet, areas. In the other example, the Bielany and Kabaty Woods are characterised by similar habitat types, with a considerable share of old stand, and they are both located in a similar distance from the city centre.

According to the work done by Dickman (1987), the richness of small mammal species within a city can be maintained through a network of woodland areas over 0.65 ha in size. All of the areas examined in the present study are far larger than this recommended size, hence, the reserves in Warsaw likely ensure the effective protection of mammals associated with woodlands. However, in case of the smaller sites studied - especially where these are surrounded by areas subject to extensive anthropogenic influence - changes in species composition were apparent and the penetration by species associated with open areas or the presence of people was also observed. Nevertheless, these results suggest that the system of protected areas in Warsaw provide a safeguard to populations of most small mammal species. However, a further key element to the protection of these small mammals is the prevention of additional damage to areas adjacent to reserves, as well as the retention and maintenance of the ecological corridors that connect the land between different sites.

\section{References}

Andrzejewski R., Babińska-Werka J., Gliwicz J. 1978. Synurbization processes in population of Apodemus agrarius. I. Characteristics of populations in an urbanization gradient. Acta Theriologica, 23, 341-358.

Babińska-Werka J., Gliwicz J., Goszczyński J. 1979. Synurbization processes in population of Apode- 
mus agrarius. II. Habitats of the striped-field mouse in town. Acta Theriologica, 24, 405-415.

Baker P.J., Ansell R.J., Dodds P.A., Webber C.E., Harris S. 2003. Factors affecting the distribution of small mammals in an urban area. Mammal Review, $33,95-100$.

Buckmaster A., Osborne W., Webb N. 2010. The loss of native terrestrial small mammals in large urban reserves in the Australian Capital Territory. Pacific Conservation Biology, 16, 36-45.

Cavia R., Rubén G., Suárez O.L. 2009. Changes in rodent communities according to the landscape structure in an urban ecosystem. Landscape and Urban Planning, 90, 11-19.

Chao A. 1984. Non-parametric estimation of the number of classes in a population. Scandinavian Journal of Statistics, 11, 265-270.

Czerwiński Z., Czępińska-Kamińska D., Zielony R. 2003. Natural environment of Las Kabacki (in Polish). Wydawnictwo SGGW, Warszawa.

Dickman C.R. 1987. Habitat fragmentation and vertebrate species richness in an urban environment. Journal of Applied Ecology, 24, 337-351.

Dickman C.R., Doncaster C.P. 1987. The ecology of small mammals in urban habitats. I. Populations in a patchy environment. Journal of Animal Ecology, 56, 629-640.

Faulkner S. 2004. Urbanization impacts on the structure and function of forested wetlands. Urban Ecosystems, 7, 89-106.

Gomes V., Ribeiro R., Carretero M.A. 2011. Effects of urban habitat fragmentation on common small mammals: species versus communities. Biodiversity and Conservation, 20, 3577-3590.

Gortat T., Barkowska M., Gryczyńska-Siemiątkowska A., Pieniążek A., Kozakiewicz A., Kozakiewicz M. 2014. The effect of urbanization - small mammal communities in a gradient of human pressure in Warsaw city, Poland. Polish Journal of Eco$\log y, 62,163-172$.

Goszczyński J., Jabłoński P., Lesiński G., Romanowski J. 1993. Variation in diet of tawny owl Strix aluco L. along an urbanization gradient. Acta Ornithologica, 27, 113-123.

Gryz J., Krauze D. 2007. Analysis of owl pellets as noninvasive method of finding rare species of mam- mals (in Polish with English summary). Studia i Materialy CEPL, 16, 431-437.

Gryz J., Krauze D., Goszczyński J. 2008. The small mammals of Warsaw as based on the analysis of tawny owl (Strix aluco) pellets. Annales Zoologici Fennici, 45, 281-285.

Gryz J., Krauze-Gryz D. 2013. Występowanie puszczyka Strix aluco na terenie Warszawy w latach 2005-2010. Ornis Polonica, 54, 221-217.

Gryz J., Lesiński G., Kowalski M., Krauze D. 2012. Skład pokarmu puszczyka Strix aluco w Puszczy Białowieskiej. Chrońmy Przyrodę Ojczysta, 68, 100-108.

Heisler L.M., Somers C.M., Poulin R.G. 2015. Owl pellets: a more effective alternative to conventional trapping for broad-scale studies of small mammal communities. Methods in Ecology and Evolution, 7, 96-103.

Hutcheson K. 1970. A test for comparing diversities based on the Shannon formula. Journal of Theoretical Biology, 29, 151-154.

Janova E., Heroldova M. 2016. Response of small mammals to variable agricultural landscapes in Central Europe. Mammalian Biology, 81, 488-493.

Jędrzejewski W., Jędrzejewska B., Zub K., Ruprecht A.L., Bystrowski C. 1994. Resource use by tawny owls Strix aluco in relation to rodent fluctuations in Białowieża National Park, Poland. Journal of Avian Biology, 25, 308-318.

Krauze-Gryz D., Lesiński G., Pieniążek A., Romanowski J., Owsianka M., Prus M. 2016. Ssaki Parku Skaryszewskiego w Warszawie (in Polish with English summary). In: Park Skaryszewski w Warszawie (ed.: J. Romanowski). Wydawnictwo Uniwersytetu Kardynała Stefana Wyszyńskiego, Warszawa, 215-226.

Krojerová-Prokešová J., Hormolka M., Barančeková M., Heroldová M., Baňař P., Kamler J., Purchart L., Suchomel J., Zejda J. 2016. Structure of small mammal communities on clearings in manager Central European Forests. Forest Ecology and Management, 367, 41-51.

Lesiński G., Blicharski M., Sielecki M. 1998. The locality of the northern birch mouse (Sicista betulina) near Warsaw (in Polish with English summary). Kulon, 3, 101-103. 
Lesiński G., Fuszara E., Kowalski M. 2001. Characteristics of an urban community of bats in Warsaw (in Polish with English summary). Nietoperze, 2, 3-17.

Lesiński G., Gryz J. 2008. Localities of three rare mammal species in central and northeastern Poland. Fragmenta Faunistica, 51, 63-69.

Lesiński G., Gryz J. 2012. How protecting a suburban forest as a natural reserve effected small mammal communities. Urban Ecosystems, 15, 103-110.

Lesiński G., Gryz J., Kowalski M. 2008. Does the diet of an opportunistic raptor, the tawny owl Strix aluco, reflect long - term changes in bat abundance? A test in central Poland. Folia Zoologica, 57, 258-263.

Lesiński G., Gryz J., Kowalski M. 2009. Bat predation by tawny owls Strix aluco in differently humantransformed habitats. Italian Journal of Zoology, 76, 415-421.

Lesiński G., Romanowski J., Gryz J., Olszewski A., Kowalski M., Krauze-Gryz D., Olech B., Pepłowska-Marczak D., Tarłowski A. 2013. Small mammals of Kampinos National Park and its protection zone, as revealed by analyses of the diet of tawny owls Strix aluco. Fragmenta Faunistica, 56, 65-81.

Luniak M. 2010. Nature of Warsaw Bielany (in Polish). MIIZ PAN, Warszawa.

Łaszek C., Sendzielska B. 1989. Protected natural objects of Warsaw Voivodship (in Polish). Centralny Ośrodek Informacji Turystycznej, Warsaw.

Łopucki R., Mróz I., Berliński Ł., Burzych M. 2013. Effects of urbanization on small-mammal communities and the population structure of synurbic species: an example of a medium-sized city. Canadian Journal of Zoology, 91, 554-561.

Marzluff J.M., Shulenberger E., Endlicher W., Alberti M., Bradley G., Ryan C., Simon U., ZumBrunner C. 2008. Urban ecology an international perspective on the interaction between humans and nature. Springer, New York.

McKinney M.L. 2008. Effects of urbanization on species richness: A review of plants and animals. $U r$ ban Ecosystems, 11, 161-176.

Mikkola H. 1983. Owls of Europe. T and AD Poyser, Calton.

Popczyk B., Lesiński G., Baumann A., Wojtowicz B. 2008. Kuhl's pipistrelle, Pipistrellus kuhlii (Kuhl, 1817) or Pipistrellus lepidus Blyth, 1845, in Central
Poland - accidental record or a result of expansion? Nyctalus (N.F.), 13, 279-281.

Pucek Z. 1984. Key to vertebrates of Poland: mammals. PWN, Warsaw.

Raczyński J., Ruprecht A.L. 1974. The effect of digestion on the osteological composition of owl pellets. Acta Ornithologica, 14, 25-36.

Redpath S.M. 1995. Habitat fragmentation and the individual: tawny owls Strix aluco in woodland patches. Journal of Animal Ecology, 64, 652-661.

Romanowski J., Lesiński G., Bardzińska M. 2016. Drobne ssaki terenów podmiejskich Warszawy w pokarmie puszczyka Strix aluco. Studia Ecologiae et Bioethicae,14, w druku.

Ruprecht A.L. 1979. Criteria to identify species of the subgenus Sylvaemus Ognev and Vorobiev, 1923 (Rodentia: Muridae) (in Polish). Przeglad Zoologiczny, 23, 340-350.

Ruprecht A.L. 1987. The key to identify mandibles of bats of Polish fauna (in Polish). Przeglad Zoologicz$n y, 31,89-105$.

Stolarz P. 2011. The nature of Bagno Jacka reserve (in Polish). Centrum Ekologii Człowieka, Warsaw.

Stolarz P., Lesiński G. 2012. Vertebrates in diet of tawny owl Strix aluco in nature reserve 'Bagno Jacka' and surrounding area (in Polish with English summary). Kulon, 17, 107-110.

Sunde P., Bølstad M.S. 2004. A telemetry study of the social organization of a tawny owl (Strix aluco) population. Journal of Zoology, 263, 65-76.

Tothmeresz B. 1995. Comparison of different methods for diversity ordering. Journal of Vegetation Science, 6, 283-290.

Vergnes A., Kerbiriou C., Clergeau P. 2013. Ecological corridors also operate in an urban matrix: A test case with garden shrews. Urban Ecosystems, 16, 511-525.

Wojtatowicz J. 2005. Nature of Warsaw, objects and areas under protection (in Polish). Biuro Ochrony Środowiska Urzędu M. St. Warszawy, Warsaw.

Yalden D.W., Morris P.A. 1990. The analysis of owl pellets. Occasional publication of the Mammal Society No. 13. Mammal Society, London.

Żmihorski M., Gryz J., Krauze-Gryz D., Olczyk A., Osojca G. 2011. The tawny owl Strix aluco as a material collector in faunistic investigations: the case study of small mammals in NE Poland. Acta Zoologica Lituanica, 21, 185-191. 